\title{
A Research-Based Approach to Participation Assessment: Evolving Beyond Problems to Possibilities
}

\author{
Joan Flaherty \\ University of Guelph \\ HS Chris Choi \\ University of Guelph \\ Novie Johan \\ University of Surrey
}

This research study, undertaken across a department, presents the results of two focus groups in which twenty undergraduate students offer their views on participation assessment and its underlying goal of student engagement. Barriers to fairly assessing participation are discussed along with their solutions. Assessing participation, though, isn't just about identifying and then dealing with problems, as necessary as that is. It's also about fostering and acknowledging personal and academic growth on the part of the student and, as strange as this may sound, on the part of the professor.

\section{Introduction}

$\mathrm{T}$ his paper uses a fundamental pedagogical principle - learner centredness - to address two issues that continue to vex most post-secondary educators: how to assess student participation and, perhaps more tellingly, how to achieve its underlying goal of student engagement. All the conclusions were derived from our School's students during two 90-minute focus groups. The first focus group consisted of 11 participants, all third- or fourth-year students; the second group consisted of nine participants, all in second year.

Directly asking students for their views on these two issues seemed like a logical approach since both issues intimately involve the students themselves. It also seemed like a logical approach since faculty efforts to address these issues have so often been impeded by factors that are either beyond their control, such as increasingly large and anonymous 
classes or perceived as their own inherent failings, such as personal bias.

The study was originally intended for a specific, somewhat limited, audience: our faculty colleagues in the School of Hospitality and Tourism Management at University of Guelph. We wanted to know our students better and to share among ourselves ways of assessing participation fairly and engaging students fully. However, we think the insights we achieved on all counts may resonate with students and their teachers within a broad range of disciplines.

\section{What is Participation?}

Before participation can be assessed, it has to be defined. As the literature reveals, however, defining participation is not a straightforward task. It's hard to imagine any educator disagreeing with the notion that participation involves speaking up, "initiating questions, answers and giving comments" (Kao \& Gansneder, 1995 p. 136). Some, though, might balk at accepting the broader view offered by Forster, Taylor, and Davis (2002), who credit being open to others' ideas and adaptable as elements of participation. And any educator who accepts the latter's definition would probably be open to (if not enthusiastic about) its logical conclusion: full participation may involve complete silence (Lave \& Wenger, 1991).

Our focus group participants expressed a similar range of views as they answered the first question posed to them: "How do you define participation?" Two distinct categories of response emerged.

The second-year students defined participation as having "a face to face" component. Participation, for them, meant actively speaking up in class. Other forms of participation that they had experienced, such as written comments submitted after class or electronic participation, based on e-mail or chatting, were unanimously rejected by this group. One student characterized it as "not really participation because you are behind a mask of a computer." Another explained her rejection on this basis: "you are communicating, but you are not being social."
In contrast, the more senior students offered a much broader definition. Participation, which one defined as "active involvement," could take different forms, which do not necessarily involve speaking up in class: written comments sent to the professor, weekly quizzes, and even attendance were all cited as acceptable forms of participation. The student who argued that attendance could be a legitimate form of participation explained that "actively listening is part of it." Some students simply are not comfortable talking in front of others, but they come to class regularly and are actively engaged in the material. This engagement should be acknowledged. In contrast, those students who attend infrequently but speak expansively when they do show up should not be rewarded with high participation grades. Their lack of attendance indicates a lack of commitment to the course.

\section{What are the Benefits of Participation?}

To assess participation, faculty need clearly-defined benchmarks or goals. The ensuing paragraphs essentially explain the goals of participation from the students' perspective.

Considerable overlap existed between the two focus groups' responses to this question. The benefits cited included the following: motivate students to come to class prepared; encourage attendance; foster understanding of and interest in the material; help students remember the material; and help students stay focused during class discussions. For the most part, these responses - somewhat predictably - centre on increased learning of the material.

The benefits of classroom participation also extend to the work world - participation makes students known to faculty, who can then be approached for a job reference; and it hones speaking skills, which are useful in the workplace.

Another benefit that was discussed - and, in fact, emphasized - by the second-year group involved self development and sense of community. No students actually used those terms to describe the benefits, but participation, which they had earlier de- 
fined as actively speaking up in class, was important insofar as it helped "you learn a lot about yourself." Part of that learning involved "the process of being comfortable (with yourself) in the class;" gaining "insight about yourself" and "self confidence in your own ability."

Participation also leads to a better understanding of others. Being exposed to "many perspectives and life experiences" was seen as essential in terms of developing one's social skills. And, as one student declared, "You need to learn how to participate... [because]...you are here to learn social skills, not only the actual knowledge."

Several second-year students also emphasized the important role that participation plays in making them feel at home in the unfamiliar and somewhat daunting environment of first-year university. One student summarized this sentiment: "It's a little scary to have a participation mark, because you don't know the people yet. But at the same time...it's good to have participation just so people can get to know each other and start to feel comfortable in engaging themselves." Another remarked on how participation had allowed her to reinvent her persona from "[the] shy kid in high school" to someone who "at the end [knew] almost everybody and [was] very comfortable to talk with people."

\section{How is Participation Assessment Viewed by Students?}

While all 20 students agreed that participation is important and needs to be a major part of their education, they had conflicting views on participation assessment: eight of the nine students in the secondyear group said that they would participate even if no grade were assigned; no one seemed particularly attached to the notion that they had to be rated on their participation. However, all 11 students from the more senior year emphatically agreed with the statement, "If [a professor] expects participation, there should be a grade attached to it."

In any case, both groups expressed concern about participation assessment based on the following issues:

\section{Lack of clear participation assessment criteria.} Typically the criteria had not been clearly explained, and because every professor seemed to approach assessment differently, students were left wondering how they were being graded and whether or not the criteria themselves were fair (eg. did they take into account the course objectives, the students' different learning styles, personalities, and English language ability?).

Quantity versus quality. Students expressed frustration over irrelevant, repetitious discussion that occurred when their classmates tried to fill a quota of comments in order to receive high participation grades. One student, however, commented that "quantity is also important;" in other words, to receive the maximum benefit from participation, one has to participate a lot.

A setting that isn't appropriate. In some classes, participation is inappropriate and shouldn't be assessed: classes where students cannot easily see and hear each other because of the physical set up (eg. fixed seating in rows) or the number of students in the room; and classes that deal primarily with factual information (as opposed to philosophical, discussion-based courses).

The professor's ability/desire to assess fairly and objectively. This was, by far, the largest concern in both groups. Students expressed doubt that the professor was assessing fairly when he or she demonstrated the following behaviours or attitudes:

- seemed in a hurry and focused on eliciting "gunfire responses" (rather than facilitating a discussion) or, alternatively, allowed discussions to go on too long;

- repeatedly asked the same student(s) while ignoring others;

- denigrated student comments;

- provided no response to student comments;

- did nothing to alleviate student fears of being embarrassed or being "wrong;" and

- did not learn students' names, use name cards, or take attendance. 
One student summed up a recurring sentiment when he said, "so much comes down to the Prof."

\section{Discussion}

Many faculty include a participation grade in their courses as a way of promoting student engagement. Assessing this engagement, however, is difficult. It's hard, after all, in the present climate of increasing class size and faculty workload to monitor, reflect upon, and assign a numerical value to individual student contributions. An additional problem lies in the discrepancy between students' expectations of their grades and what the faculty member believes they deserve (Gilson, 1994; Melvin 1988).

Information gleaned from the two focus groups might be helpful in addressing these concerns. For example, the following student suggestions are concrete and relatively straightforward for faculty to implement:

- Explain the evaluation criteria and the assessment method at the start of the course. This doesn't just ensure that the students understand how their participation is being measured; it also ensures that the professor has thought about it thoroughly and knows from the outset exactly what it involves.

- Use more than one measure to assess participation.

- Learn the students' names or use name cards.

Most of the student comments, though, were not centred on the nuts and bolts issue of how to assess participation. They centred on the more delicate minefield of faculty personalities and capabilities. In short, the students openly questioned their professors' credibility in terms of being able to assess participation. Building up (or in a very few cases, maintaining) this credibility might require faculty to work on the following classroom management skills:

Tolerate. Faculty must recognize that "quality" and "quantity" are not necessarily antithetical. The path leading to insightful, valuable comments may be a winding one, full of vaguely expressed ideas and questionable logic. Tolerating - and even encouraging - the latter is sometimes the only way to reach those valuable comments.

Moderate. Faculty must balance the above objective with an efficient use of class time. That means being able to moderate a complex discussion so that no one in the room questions that course objectives are being met, that time is being spent well, and that everyone has an equal chance to have their say and be fairly assessed.

Advocate. Making sure that everyone in the class "has an equal chance to have their say" isn't simply a matter of acknowledging everyone who raises their hand. Faculty may need to advocate on behalf of those students who do have something to say, but are reluctant to enter into the fray. Students, who are quiet, shy, and whose first language is not the language of instruction, may be part of this group who do want to participate, but who need active encouragement from the professor. And last, as strange as this may sound, faculty may also need to advocate on their own behalf. Focus group participants used a recurring adjective to describe those professors who fostered an engaged classroom climate: passionate. Faculty who showed a passion for the material and for teaching it, were more likely to be perceived as credible and more likely to foster a climate of engagement. In other words, students would not only participate more in this professor's class; they would also be more likely to accept as valid his or her assessment of their participation.

\section{Conclusion}

Faculty often feel that the only way to have student involvement is to assign a grade to that involvement. Our focus group findings, though, show that this is not necessarily the case. The second-year students sent out a clear message: the goal of personal growth is a powerful motivator for their engagement. Therefore, perhaps faculty do not need to assess par- 
ticipation in order to get participation. Perhaps what they need, instead, is to create a classroom environment that fosters the student goals of self and social growth. The participation that ideally results from this environment would reflect the academic and personal growth of both student and faculty member.

\section{References}

Forster, P., Taylor, P., \& Davis, C. (2002). The sherpa-student role with a graphics calculator: Empowering or disempowering? Proceedings of the 23rd Annual Conference of the Mathematics Education Research Group of Australasia. Merga, Auckland.

Gilson, C. (1994). Of dinosaurs and sacred cows: The grading of classroom participation. Journal of Management Education, 18(2), 227-236.

Kao, C., \& Gansneder, B. (1995). An assessment of class participation by international graduate students. Journal of College Student Development, 36, 132-140.

Lave, J., \& Wenger, E. (1991). Situated learning: Legitimate peripheral participation. Cambridge, MA: Cambridge University Press.

Melvin, K. B. (1988). Rating class participation: The prof/peer method. Teaching of Psychology, 15(3), 137-139. 